\title{
Rugby World Cup 2019 injury surveillance study
}

\author{
CW Fuller, ${ }^{1,2}$ PhD; A Taylor, ${ }^{2}$ MSc; M Douglas, ${ }^{2}$ BE (Mech); \\ M Raftery, ${ }^{2}$ MBBS
}

${ }^{1}$ Colin Fuller Consultancy Ltd, Sutton Bonington, United Kingdom

2 World Rugby, World Rugby House, 8-10 Pembroke Street Lower, Dublin 2, Ireland

\section{Corresponding author: C Fuller (colinfullerconsultancy@gmail.com)}

Background: Full contact team sports, such as rugby union, have high incidences of injury. Injury surveillance studies underpin player welfare programmes in rugby union.

Objective: To determine the incidence, severity, nature and causes of injuries sustained during the Rugby World Cup 2019.

Methods: A prospective, whole population study following the definitions and procedures recommended in the consensus statement for epidemiologic studies in rugby union. Output measures included players' age (years), stature $(\mathrm{cm})$, body mass $(\mathrm{kg})$, playing position, and group-level incidence (injuries/1000 player-hours), severity (daysabsence), injury burden (days absence/1000 player-hours), location (\%), type (\%) and inciting event (\%) of injuries.

Results: Overall incidences of injury were 79.4 match injuries/1000 player-match-hours (95\% CI: 67.4 to 93.6) and 1.5 training injuries/1000 player-training-hours (95\% CI: 1.0 to 2.3). The overall mean severity of injury was 28.9 (95\% CI: 20.0 to 37.8 ) days absence during matches and 14.8 (95\% CI: 4.1 to 25.5) days absence during training. The most common locations and types of match injuries were head/face (22.4\%), posterior thigh $(12.6 \%)$, ligament sprain $(21.7 \%)$ and muscle strain $(20.3 \%)$; the ankle $(24.0 \%)$, posterior thigh $(16.0 \%)$, muscle strain $(44.0 \%)$ and ligament sprain $(16.0 \%)$ were the most common locations and types of injuries during training. Tackling $(28.7 \%)$, collisions $(16.9 \%)$ and running (16.9\%) were responsible for most match injuries and non-contact $(36.0 \%)$ and contact $(32.0 \%)$ rugby skills activities for training injuries. Conclusion: The incidence, severity, nature and inciting events associated with match and training injuries at Rugby World Cup 2019 were similar to those reported for Rugby World Cups 2007, 2011 and 2015.

Keywords: Rugby World Cup, injury incidence, injury severity, injury burden, injury risk

S Afr J Sports Med 2020;32:1-6. DOI: 10.17159/2078-516X/2020/v32i1a8062

Athletes competing in contact team sports, such as rugby union, generally experience higher incidences of injury than those competing in non-contact and semi-contact team sports. World Rugby, as the international governing body for rugby union, addresses its duty of care by implementing an evidence-based player welfare strategy underpinned by risk management principles. ${ }^{[1-3]}$ Central to this player welfare strategy is a comprehensive programme of injury surveillance studies implemented at all major men's and women's international rugby tournaments.

World Rugby's flagship competition is the men's Rugby World Cup (RWC) which is contested every 4 years. The main objectives of the present study were to preserve the World Rugby's programme of injury surveillance studies for the RWC and to compare the RWC 2019 match injury results with those previously published for the 2007, 2011 and 2015 RWCs respectively.

\section{Methods}

\section{Study definitions and procedures}

The definitions and procedures used in this study were compliant with the consensus statement on injury definitions and data collection procedures for studies of injuries in rugby union $^{[4]}$ and were also consistent with the procedures used for RWCs 2007, 2011 and 2015 studies.[5-7] World Rugby's Institutional Ethics Committee approved the study and all players taking part in RWC 2019 consented to their data being included in this study. The study took place in Japan over a 7 week period commencing on Monday 16 September 2019. The first match was played on Friday 20 September and the final match on Saturday 2 November 2019. Three scheduled RWC 2019 group stage matches were cancelled due to adverse weather conditions.

Six weeks prior to the start of the competition, the 20 participating countries received a guidance document explaining the definitions and reporting procedures. Each player's baseline information, consisting of their normal playing position, date of birth, stature $(\mathrm{cm})$ and body mass $(\mathrm{kg})$, was obtained with data reported as population means (standard deviation). Equivalent anthropometric data for players competing in the 2007, 2011 and 2015 RWCs were retrieved from previous publications. ${ }^{[5-7]}$ Match exposures were based on 15 players (backs: 7; forwards: 8) being exposed for 80 minutes per match. No allowances were made for players temporarily (as a result of medical treatment) or permanently (due to the receipt of yellow or red cards) missing during a match. None of the matches required extra time. Training exposures were recorded based on the number of players (backs, forwards) attending team training sessions, and the number, length (in minutes) and structure of the sessions (preparation: warm up, cooldown, rugby skills: full-contact, semi-contact, non-contact, conditioning: with weights, without weights; other activities).

For the RWC, the definition of an injury was: 'Any physical complaint sustained by a player during a RWC match or training session that prevented the player from taking a full part in all training activities or match play for more than 1 day following the day of injury, irrespective of whether match or training sessions were actually scheduled'. ${ }^{[4]}$ The definition of an illness was: 'Any medical condition sustained during the period of the RWC study that prevented the player from taking a full part in all training activities and/or match play for more than 1 day following the day of onset of the illness.'. Injuries 
were reported as recurrences based on the clinical judgement of the injured player's medical team using the definition: 'An injury of the same type and at the same site as an index injury and which occurred after the player's return to full participation from the index injury'. ${ }^{[4]}$ Team physicians/physiotherapists were responsible for reporting injuries/illnesses, including the date of injury/illness, the date of return-to-play/training, injury location, type, Orchard Sports Injury Coding System (v8) code, ${ }^{[8]}$ and recurrence. All concussion injury reports were cross-checked for consistency with the results reported for match day concussion assessments. When necessary, injuries and illnesses were followed up for three months after the final match of RWC 2019 to obtain return-to-play/training dates. Beyond this time, team physicians provided estimated return-to-play/training dates based on a player's condition at that time (eight injuries). Where appropriate, risk factors, such as playing position, time of match injury $(0-20 ; 21-40+; 41-60 ; 61-80+$ minutes), activity at time of injury and whether the player was removed from play/training when injured, were reported. In this study, match and training results are reported separately as the number of injuries/1 000 player-hours of exposure with 95\% confidence intervals (CI) and injury severities are reported as the mean and median (days; 95\% CI). Injury burden, the product of incidence and mean severity of injury, $[2,9,10]$ is reported as days-absence/1 000 player-hours (95\% CI). Equivalent injury data for the 2007, 2011 and 2015 RWCs were retrieved from other published reports. [5-7]

\section{Statistical analysis}

Statistical comparisons of players' anthropometric data were calculated using unpaired t-tests. ${ }^{[11]}$ Numbers of injuries were compared using chi-squared tests, z-tests were used to compare incidences and mean severities of injury, and MannWhitney U-tests for median severities. ${ }^{[11]}$ Trends in values over the four RWCs $(2007,2011,2015,2019)$ were calculated using linear regression analyses and are reported with the slope of the regression lines and $\mathrm{R}^{2}$ values.[11] The number of data comparisons made in this study create the potential for some comparisons to appear as statistically significant at the $\mathrm{p} \leq 0.05$ level when they may have occurred by chance; for this reason, exact $\mathrm{p}$-values are reported for statistical tests.

\section{Results}

Six hundred and forty-six players (backs: 284; forwards: 362) representing 20 countries took part in this study and provided baseline anthropometric data (Table 1).

There were no significant trends in players' age (backs: slope $=0.024$ years/year, $\mathrm{R}^{2}=0.12, \mathrm{p}=0.653$; forwards: slope $=$ -0.051 years/year, $R^{2}=0.46, p=0.332$ ), stature (backs: slope $=$ $0.018 \mathrm{~cm} /$ year, $\mathrm{R}^{2}=0.31, \mathrm{p}=0.443$; forwards: slope $=-0.068$ $\mathrm{cm} /$ year, $\mathrm{R}^{2}=0.72, \mathrm{p}=0.151$ ) or body mass (backs: slope $=$ $0.044 \mathrm{~kg} /$ year, $\mathrm{R}^{2}=0.08, \mathrm{p}=0.726$; forwards: slope $=0.10$ $\mathrm{kg} /$ year, $\mathrm{R}^{2}=0.50, \mathrm{p}=0.296$ ) over the period 2007 to 2019 .

\section{Incidence, severity and injury burden}

One hundred and forty-three match injuries (backs: 79; forwards: 64) were sustained during the 45 matches played (group stage: 37; knockout stage: 8 ), which equate to 1800 player-match-hours (backs: 840; forwards: 960). Over the 7 week period, a total of 16220 (backs: 7 168; forwards: 9 052) player-training-hours ( 3 teams did not return player-traininghours) and 25 training injuries (backs: 11; forwards: 14) (all teams returned training injuries) were recorded: incidence of training injuries was based on the results provided by the 17 teams returning both injury and exposure data. No catastrophic spinal or career-ending injuries were reported during the tournament. Two illnesses were reported during the tournament (tonsillitis: 1; ear infection: 1). The illnesses correspond to a period prevalence of $0.3 \%$ over the period of the competition. No further analysis of these illnesses was undertaken due to their small number.

The incidences and severities of match injuries sustained at RWC 2019 are presented in Table 2. It shows that the incidence of injury was higher for backs than forwards (difference $=27.4$ injuries/1 000 player-match-hours, $95 \% \mathrm{CI}=1.0$ to $53.8, \mathrm{p}=$ 0.041 ). There were no trends in the incidences of match injuries over the four RWCs for backs (average value $=93.0$ injuries $/ 1$ 000 player-match-hours, slope $=0.94$ injuries $/ 1000$ playermatch-hours/year, $\mathrm{R}^{2}=0.49, \mathrm{p}=0.299$ ) or forwards (average value $=79.2$ injuries $/ 1000$ player-match-hours, slope $=-1.4$ injuries/1 000 player-match-hours/year, $\mathrm{R}^{2}=0.72, \mathrm{p}=0.151$ ). There was no significant difference between the severities of match injuries sustained by backs and forwards at RWC 2019 (mean severity: difference $=-0.9$ days, $95 \% \mathrm{CI}=-19.0$ to 17.2 , $\mathrm{p}$ $=0.920$; median severity: difference $=-1.0$ days, $p=0.992$ ). There was no trend in the severity of match injuries over the four RWCs for backs (mean severity: slope $=1.1$ days/year, $R^{2}=0.70$, $\mathrm{p}=0.162$; median severity: slope $=0.00$ days/year, $\mathrm{R}^{2}<0.01, \mathrm{p}=$ $1.000)$ but an increasing trend for forwards (mean severity: slope $=1.4$ days/year, $\mathrm{R}^{2}=0.91, \mathrm{p}=0.049$; median severity: slope $=0.25$ days $/$ year, $R^{2}=0.83, p=0.087$ ).

The incidences and severities of training injuries sustained at RWC 2019 are also included in Table 2. The incidence of training injuries was higher for forwards than backs (difference $=0.26$ injuries $/ 1000$ player-training-hours, $95 \% \mathrm{CI}=-0.9$ to 1.5 , $\mathrm{p}=0.674$ ). There were no significant trends in the incidence of

Table 1. Anthropometric data of players competing at RWC 2019

\begin{tabular}{lccc}
\hline Playing position (n) & $\begin{array}{c}\text { Age } \\
\text { (years) }\end{array}$ & $\begin{array}{c}\text { Stature } \\
(\mathbf{c m})\end{array}$ & $\begin{array}{c}\text { Body mass } \\
(\mathbf{k g})\end{array}$ \\
\hline Backs (n=284) & $27.3(3.5)$ & $182.6(6.0)$ & $91.2(9.1)$ \\
Halves (n=101) & $27.7(3.6)$ & $179.0(5.9)$ & $85.1(7.5)$ \\
Inside backs (n=76) & $27.7(3.2)$ & $185.5(4.5)$ & $97.5(7.0)$ \\
Outside backs (n=107) & $26.7(3.6)$ & $183.9(5.4)$ & $92.6(8.1)$ \\
Forwards (n=362) & $27.3(3.8)$ & $188.3(7.0)$ & $111.8(9.2)$ \\
Front row (n=169) & $27.2(3.9)$ & $183.7(4.5)$ & $114.4(9.1)$ \\
Second row (n=80) & $28.0(3.6)$ & $197.3(4.6)$ & $114.8(6.6)$ \\
Back row (n=113) & $27.1(3.7)$ & $188.9(5.0)$ & $105.8(7.9)$ \\
All players (n=646) & $27.3(3.7)$ & $185.8(7.2)$ & $102.8(13.7)$ \\
p value* & 1.000 & $<0.001$ & $<0.001$ \\
\hline
\end{tabular}

Data are expressed as Mean (SD). * indicates Backs vs Forwards RWC, Rugby World Cup; $n$, number of players 
Table 2. Incidences and mean and median severities of injuries sustained by backs and forwards during matches and training

\begin{tabular}{|c|c|c|c|}
\hline \multirow{2}{*}{$\begin{array}{l}\text { Activity / } \\
\text { Playing position (n) }\end{array}$} & \multirow{2}{*}{$\begin{array}{c}\text { Incidence Injuries / } \\
1000 \text { player-hours } \\
(95 \% \text { CI) } \\
\end{array}$} & \multicolumn{2}{|c|}{ Severity Days (95\% CI) } \\
\hline & & Mean & Median \\
\hline \multicolumn{4}{|l|}{ Match injuries (n) } \\
\hline Backs $(n=79)$ & $94.0(75.4-117.3)$ & $28.5(17.2-39.8)$ & $8(6-11)$ \\
\hline Halves $(\mathrm{n}=27)$ & $112.5(77.1-164.0)$ & $24.6(12.6-36.6)$ & $7(6-36)$ \\
\hline Inside backs $(\mathrm{n}=20)$ & $83.3(53.8-129.2)$ & $55.6(17.1-94.0)$ & $12(8-67)$ \\
\hline Outside backs (n=32) & $88.9(62.9-125.7)$ & $14.9(7.9-21.9)$ & $6.5(5-10)$ \\
\hline Forwards $(n=64)$ & $66.7(52.2-85.2)$ & $29.4(15.3-43.4)$ & $9(6-15)$ \\
\hline Front row $(\mathrm{n}=29)$ & $80.6(56.0-115.9)$ & $18.6(9.4-27.7)$ & $8(4-23)$ \\
\hline Second row $(\mathrm{n}=8)$ & $33.3(16.7-66.7)$ & $39.0(0-84.0)$ & $14(4-197)$ \\
\hline Back row $(n=27)$ & $75.0(51.4-109.4)$ & $38.1(9.1-67.1)$ & $9(5-28)$ \\
\hline All players (n=143) & $79.4(67.4-93.6)$ & $28.9(20.0-37.7)$ & $6(3-13)$ \\
\hline p-value* & 0.041 & 0.920 & 0.992 \\
\hline \multicolumn{4}{|l|}{ Training injuries (n) } \\
\hline Backs $(n=10)$ & $1.4(0.8-2.6)$ & $17.0(0-42.3)$ & $5.5(2-15)$ \\
\hline Forwards $(n=15)$ & $1.7(1.0-2.7)$ & $13.3(6.5-20.1)$ & $7(2-27)$ \\
\hline All players $(n=25)$ & $1.5(1.0-2.3)$ & $14.8(4.1-25.5)$ & $6(3-13)$ \\
\hline p-value* & 0.674 & 0.779 & 0.978 \\
\hline
\end{tabular}

* indicates Backs vs Forwards

$n$, number of injuries; CI, confidence interval

Table 3. Match injuries as a function of injury location and playing position

\begin{tabular}{|c|c|c|c|}
\hline \multirow{2}{*}{ Injury location } & \multicolumn{3}{|c|}{$\%$ Proportion of injuries $(95 \% \mathrm{CI})$} \\
\hline & Backs & Forwards & All players \\
\hline Head/neck injuries & $25.3(15.7-34.9)$ & $28.1(17.1-39.1)$ & $26.6(19.3-33.8)$ \\
\hline Head/face & $22.8(13.5-32.0)$ & $21.9(11.7-32.0)$ & $22.4(15.5-29.2)$ \\
\hline Neck/cervical spine & $2.5(0-6.0)$ & $6.3(0.3-12.2)$ & $4.2(0.9-7.5)$ \\
\hline Upper limb injuries & $16.5(8.3-24.6)$ & $20.3(10.5-30.2)$ & $18.2(11.9-24.5)$ \\
\hline Shoulder/clavicle & $6.3(1.0-11.7)$ & $9.4(2.2-16.5)$ & $7.7(3.3-12.1)$ \\
\hline Upper arm & 0.0 & $1.6(0-4.6)$ & $0.7(0-2.1)$ \\
\hline Elbow & 0.0 & $4.7(0-9.9)$ & $2.1(0-4.4)$ \\
\hline Forearm & $1.3(0-3.7)$ & $1.6(0-4.6)$ & $1.4(0-3.3)$ \\
\hline Wrist/hand/fingers & $8.9(2.6-15.1)$ & $3.1(0-7.4)$ & $6.3(2.3-10.3)$ \\
\hline Trunk injuries & $7.6(1.8-13.4)$ & $9.4(2.2-16.5)$ & $8.4(3.8-12.9)$ \\
\hline Upper back/sternum/ribs & $3.8(0-8.0)$ & $4.7(0-9.9)$ & $4.2(0.9-7.5)$ \\
\hline Abdomen & 0.0 & 0.0 & 0.0 \\
\hline Lower back/pelvis & $3.8(0-8.0)$ & $4.7(0-9.9)$ & $4.2(0.9-7.5)$ \\
\hline Lower limb injuries & $50.6(39.6-61.7)$ & $42.2(30.1-54.3)$ & $46.9(38.7-55.0)$ \\
\hline Hip/groin & $1.3(0-3.7)$ & 0.0 & $0.7(0-2.1)$ \\
\hline Anterior thigh & $10.1(3.5-16.8)$ & $3.1(0-7.4)$ & $7.0(2.8-11.2)$ \\
\hline Posterior thigh & $13.9(6.3-21.6)$ & $10.9(3.3-18.6)$ & $12.6(7.2-18.0)$ \\
\hline Knee & $8.9(2.6-15.1)$ & $15.6(6.7-24.5)$ & $11.9(6.6-17.2)$ \\
\hline Lower leg/Achilles & $3.8(0-8.0)$ & $6.3(0.3-12.2)$ & $4.9(1.4-8.4)$ \\
\hline Ankle & $8.9(2.6-15.1)$ & $6.3(0.3-12.2)$ & $7.7(3.3-12.1)$ \\
\hline Foot/toe & $3.8(0-8.0)$ & 0.0 & $2.1(0-4.4)$ \\
\hline
\end{tabular}

CI, confidence interval training injuries over the four RWCs from 2007 to 2019 for either backs (average value $=1.9$ injuries $/ 1000$ player-training-hours, slope $=0.19$ injuries/1 000 player-training-hours/year, $\mathrm{R}^{2}=$ $0.65, p=0.192$ ) or forwards (average value $=2.3$ injuries/1 000 player-training-hours, slope = 0.17 injuries/1 000 player-training-hours/year, $\left.\mathrm{R}^{2}=0.74, \mathrm{p}=0.141\right)$. There was no significant difference between the severities of training injuries sustained by backs and forwards (mean severity: difference $=3.7$ days, $95 \% \mathrm{CI}=-22.5$ to 29.9, $\mathrm{p}=0.779$; median severity: difference $=-1.0$ day, $\mathrm{p}=0.978$ ). Also, there was no trend in the mean severity (slope $=-0.22$ days $/$ year, $R^{2}=0.03$, $\mathrm{p}=0.825$ ) but a decreasing trend in the median severity (slope $=-0.38$ days/year, $R^{2}=1.00, p$ $<0.001$ ) of training injuries sustained by backs over the period 2007 to 2019 . There were no trends for forwards in the mean (slope $=-0.54$ days/year, $\mathrm{R}^{2}=0.10, \mathrm{p}=0.691$ ) or median (slope $=-0.10$ days/year, $R^{2}=0.20, p=0.553$ ) severities. In total, 4526 player-days were lost as a consequence of match (backs: 2 251; forwards: 1 879) and training (backs: 196; forwards: 200) injuries sustained in the RWC 2019. The overall match injury burden experienced was 2296 days absence/ 1000 player-match-hours (95\% CI $=1949$ to 2 705); with the injury burden for backs (2 680 days absence/1 000 player-matchhours, $95 \% \mathrm{CI}=2115$ to 3342 ) higher than that for forwards (1957, 95\% CI = 1532 to $2501, \mathrm{p}=$ 0.061 ). There were no statistically significant trends in injury burden for backs (slope $=118$ days absence/1 000 player-match-hours/year, $\mathrm{R}^{2}$ $=0.65, \mathrm{p}=0.192$ ) or forwards (slope $=73$ days absence/1 000 player-match-hours/year, $\mathrm{R}^{2}=$ $0.58, p=0.236$ ) over the period 2007 to 2019 . The overall training injury burden for RWC 2019 was 23 days absence/1 000 player-traininghours ( $95 \% \mathrm{CI}=15$ to 34 ). The training injury burden for backs was similar (24 days absence/1 000 player-training-hours, $95 \% \mathrm{CI}=15$ to 34 ) to that for forwards $(22,95 \% \mathrm{CI}=13$ to $37, \mathrm{p}=$ 0.865).

\section{Location, type and nature of injuries}

Ninety-one per cent (95\% CI $=87.0$ to 96.1 ) of match injuries were acute (backs: $92.3 \%, 95 \%$ CI $=86.4$ to 98.2 ; forwards: $90.6 \%, 95 \% \mathrm{CI}=83.5$ to 97.8; $\mathrm{p}=0.719)$ and $8.5 \%(95 \% \mathrm{CI}=3.9$ to 13.0$)$ gradual onset (backs: $7.7 \%, 95 \% \mathrm{CI}=1.8$ to 13.6 ; forwards: $9.4 \%, 95 \% \mathrm{CI}=2.2$ to $16.5 ; \mathrm{p}=0.719$ ). Of the 25 training injuries, $84.0 \%(95 \% \mathrm{CI}=69.6$ to 98.4 ) were acute (backs: $70.0 \%, 95 \% \mathrm{CI}=41.6$ to 98.4 ; forwards: $93.3 \%, 95 \% \mathrm{CI}=80.7$ to 100 ; p $=0.119)$ and $16.0 \%$ (95\% CI: 1.6 to 30.4$)$ gradual onset (backs: $30.0 \%, 95 \%$ CI $=1.6$ to 58.4 ; forwards: $6.7 \%, 95 \% \mathrm{CI}=0$ to $19.3 ; \mathrm{p}=0.119$ ). 
The proportions of match injuries sustained as functions of location and type of injury are presented in Tables 3 and 4 . There were no statistically significant trends in the proportions of the main injury locations or injury types sustained over the period 2007 to 2019 for backs or forwards, apart from an increasing trend in the proportion of head/neck injuries sustained by backs (slope $=1.6 \% /$ year, $\mathrm{R}^{2}=0.95, \mathrm{p}=$ 0.028 ).

The six most common match injuries and the six match injuries responsible for most days absence are presented in Table 5. The knee ligament group of injuries includes medial

Table 4. Match injuries as a function of injury type and playing position

\begin{tabular}{lccc}
\hline \multirow{2}{*}{ Injury type } & \multicolumn{3}{c}{$\%$ Proportion of injuries $\mathbf{( 9 5 \% ~ C I )}$} \\
\cline { 2 - 4 } & Backs & Forwards & All players \\
\hline Bone injuries & $10.1(3.5-16.8)$ & $3.1(0-7.4)$ & $7.0(2.8-11.2)$ \\
Fracture & $10.1(3.5-16.8)$ & $3.1(0-7.4)$ & $7.0(2.8-11.2)$ \\
Other bone injury & 0.0 & 0.0 & 0.0 \\
C/PNS injuries & $15.2(7.3-23.1)$ & $20.3(10.5-30.2)$ & $17.5(11.3-23.7)$ \\
Concussion & $15.2(7.3-23.1)$ & $15.6(6.7-24.5)$ & $15.4(9.5-21.3)$ \\
Nerve injury & 0.0 & $4.7(0-9.9)$ & $2.1(0-4.4)$ \\
Joint (non-bone) injuries & $27.8(18.0-37.7)$ & $31.3(19.9-42.6)$ & $29.4(21.9-36.8)$ \\
Dislocation/subluxation & $3.8(0-8.0)$ & $1.6(0-4.6)$ & $2.8(0.1-5.5)$ \\
Lesion meniscus/disc & $5.1(0.2-9.9)$ & $4.7(0-9.9)$ & $4.9(1.4-8.4)$ \\
Sprain/ligament & $19.0(10.3-27.6)$ & $25.0(14.4-35.6)$ & $21.7(14.9-28.4)$ \\
Muscle/tendon injuries & $38.0(27.3-48.7)$ & $34.4(22.7-46.0)$ & $36.4(28.5-44.2)$ \\
Haematoma/bruise & $13.9(6.3-21.6)$ & $12.5(4.4-20.6)$ & $13.3(7.7-18.9)$ \\
Muscle strain/cramp & $20.3(11.4-29.1)$ & $20.3(10.5-30.2)$ & $20.3(13.7-26.9)$ \\
Tendon injuries & $3.8(0-8.0)$ & $1.6(0-4.6)$ & $2.8(0.1-5.5)$ \\
Skin injuries & $1.3(0-3.7)$ & $4.7(0-9.9)$ & $2.8(0.1-5.5)$ \\
Abrasion & 0.0 & 0.0 & 0.0 \\
Laceration & $1.3(0-3.7)$ & $4.7(0-9.9)$ & $2.8(0.1-5.5)$ \\
Pain (undiagnosed) & $3.8(0-8.0)$ & $3.1(0-7.4)$ & $3.5(0.5-6.5)$ \\
Other injuries & $3.8(0-8.0)$ & $3.1(0-7.4)$ & $3.5(0.5-6.5)$ \\
\hline C/PNS, central & &
\end{tabular}

C/PNS, central and peripheral nervous system; $C I$, confidence interval

Table 5. The most common match injuries and the match injuries causing most days absence

\begin{tabular}{lccc|lccc}
\hline \multicolumn{3}{c|}{ Most common injuries } & \multicolumn{4}{c}{ Injuries causing most days absence } \\
\hline Injury & $\mathbf{n}$ & $\%$ & $\begin{array}{c}\text { Days } \\
\text { absence }\end{array}$ & Injury & $\begin{array}{c}\text { Days } \\
\text { absence }\end{array}$ & $\%$ & $\mathbf{n}$ \\
\hline Concussion & 22 & 15.4 & 363 & Knee ligament & 935 & 22.6 & 8 \\
$\begin{array}{l}\text { Hamstring } \\
\text { strain }\end{array}$ & 14 & 9.8 & 467 & $\begin{array}{l}\text { Knee cartilage } \\
\text { injury }\end{array}$ & 495 & 12.0 & 5 \\
Knee ligament & 8 & 5.6 & 935 & Hamstring strain & 467 & 11.3 & 14 \\
Ankle ligament & 7 & 4.9 & 95 & Concussion & 363 & 8.8 & 22 \\
$\begin{array}{l}\text { Thigh } \\
\text { haematoma }\end{array}$ & 7 & 4.9 & 43 & $\begin{array}{l}\text { Shoulder } \\
\text { dislocation }\end{array}$ & 316 & 7.7 & 2 \\
$\begin{array}{l}\text { Knee cartilage } \\
\text { injury }\end{array}$ & 5 & 3.5 & 495 & Calf muscle & 194 & 4.7 & 4 \\
All injuries & 143 & & 4130 & Alrain & & & \\
\hline
\end{tabular}

n, number of injuries; $\%$, proportion of all injuries
(5), anterior cruciate (1), posterior cruciate (1) and complex (1) ligament injuries.

As a consequence of their match injuries, 31.0\% (95\% CI: 23.4 to 49.1 ) of players (backs: $34.6 \%, 95 \%$ CI 24.1 to 45.2 ; forwards: $26.6 \%, 95 \%$ CI 15.7 to $37.4 ; \mathrm{p}=0.303)$ were removed from play immediately, $20.4 \%$ (95\% CI 13.8 to 36.2 ) of players (backs: $15.4 \%, 95 \%$ CI 7.4 to 23.4 ; forwards: $26.6 \%, 95 \%$ CI 15.7 to 37.4 ; $\mathrm{p}=0.101)$ were removed later in the game and $48.6 \%$ (95\% CI 40.4 to 68.2 ) of players (backs: $50.0 \%$, 95\% CI 38.9 to 61.1; forwards: $46.9 \%, 95 \%$ CI 34.6 to $59.1 ; p=0.711$ ) remained on the pitch until the end of the game. Of the 22 match concussions reported, 17 players $(77.3 \%)$ were removed from play immediately, three (13.6\%) players were removed later in the game and two (9.1\%) players completed the game.

Seventy-six per cent of training injuries (ankle: $24.0 \%, 95 \% \mathrm{CI}=7.3$ to 40.7 ; posterior thigh: $16.0 \%, 95 \% \mathrm{CI}=1.6$ to 30.4 ) were lower limb injuries and sixty-four per cent were muscle/tendon or joint (non-bone) injuries (muscle strains: $44.0 \%, 95 \% \mathrm{CI}=24.5$ to 63.5 ; ligament sprains: $16.0 \%, 95 \% \mathrm{CI}=1.6$ to 30.4 ). One training injury was a concussion which was identified during the training session and the player was removed immediately. A more detailed analysis of the training injuries was not undertaken due to the small number $(n=25)$ reported.

\section{Risk factors for match and training injuries}

There were no significant differences in the anthropometric characteristics of injured players compared to the overall sample of players for age (backs: difference $=0.3$ years, $95 \% \mathrm{CI}=-0.5$ to 1.1 years, $\mathrm{p}=0.478$; forwards: difference $=0.1$ years, $95 \% \mathrm{CI}=-0.8$ to $1.0, \mathrm{p}=$ 0.834 ), stature (backs: difference $=+0.7 \mathrm{~cm}$, $95 \% \mathrm{CI}=-0.8$ to $+2.2, \mathrm{p}=0.347$; forwards: difference $=-1.2 \mathrm{~cm}, 95 \% \mathrm{CI}=-2.7$ to $0.5, \mathrm{p}=$ 0.197 ) or body mass (backs: difference $=0.75$, $95 \% \mathrm{CI}=-1.5$ to $3.1, \mathrm{p}=0.478$; forwards: difference $=0.0,95 \% \mathrm{CI}=-2.1$ to $2.1, \mathrm{p}=1.000$ ). Backs sustained a higher proportion of injuries in the second half of matches compared to the first half but there was little difference for forwards (backs: first half $=$ $37.0 \%, 95 \% \mathrm{CI}=25.9$ to 48.1 , second half $=$ $63.0 \%, 95 \% \mathrm{CI}=51.9$ to $74.1, \mathrm{p}=0.026$; forwards: first half $=47.5 \%, 95 \% \mathrm{CI}=34.7$ to 60.2 , second half $=52.5 \%, 95 \% \mathrm{CI}=39.8$ to 65.3, $\mathrm{p}=0.696$ ).

Contact events were responsible for the majority of match injuries (contact: $76.0 \%$, 95\% CI: 69.6 to 82.4 ; non-contact: $24.0 \%, 95 \%$ CI: 17.6 to 30.4 ) and training injuries (contact: 70.0\%, 95\%CI: 49.9 to 90.1; non-contact: $30.0 \%, 95 \%$ CI: 9.9 to 50.1$)$. The specific 
Table 6. Match injuries sustained as a function of playing position and match activity

\begin{tabular}{lccc}
\hline \multirow{2}{*}{ Match activity } & \multicolumn{3}{c}{$\%$ Proportion of injuries $(\mathbf{9 5 \%}$ CI) } \\
\cline { 2 - 4 } & Backs & Forwards & All players \\
\hline Tackling & $29.3(19.0-39.6)$ & $27.9(16.6-39.1)$ & $28.7(21.1-36.3)$ \\
Tackled & $18.7(9.8-27.5)$ & $19.7(9.7-29.6)$ & $19.1(12.5-25.7)$ \\
Running & $21.3(12.1-30.6)$ & $11.5(3.5-19.5)$ & $16.9(10.6-23.2)$ \\
Collision* & $18.7(9.8-27.5)$ & $14.8(5.9-23.7)$ & $16.9(10.6-23.2)$ \\
Ruck & $4.0(0-8.4)$ & $6.6(0.3-12.8)$ & $5.1(1.4-8.9)$ \\
Scrum & 0.0 & $8.2(1.3-15.1)$ & $3.7(0.5-6.8)$ \\
Maul & 0.0 & $4.9(0-10.3)$ & $2.2(0-4.7)$ \\
Kicking & $2.7(0-6.3)$ & 0.0 & $1.5(0-3.5)$ \\
Lineout & 0.0 & 0.0 & 0.0 \\
Other & $5.3(0.2-10.4)$ & $6.6(0.3-12.8)$ & $5.9(1.9-9.8)$ \\
* accidental and non-accidental collisions; CI, confidence interval
\end{tabular}

period, which indicates that the main reason for the increase in mean severity continues to be related to small increases in the number of high severity injuries.

The overall lower match injury incidence recorded in RWC 2019, compared to RWC 2015 , resulted in a decrease in players' match injury burden (RWC 2019: 4130 player-daysabsence; RWC 2015: 5152 player-daysabsence); ${ }^{[7]}$ however, player-days-absence in RWC 2019 remained above those reported for RWC 2011 (4 047 player-days-absence) and RWC 2007 (2 366 player-days-absence). ${ }^{[6,7]}$ The injury burden from training injuries sustained in RWC 2019 (396 player-daysabsence) remained similar to that reported for RWC 2015 (287 player-days-absence) but activities associated with the match injuries are shown in Table 6.

There were no statistically significant trends in the proportion of injuries sustained for any of the match activities in RWC games over the period 2007 to 2019 for backs or forwards, apart from an increasing trend in the proportion of tackling injuries sustained by backs (slope $=1.7 \%$ year, $\mathrm{R}^{2}=$ $0.95, \mathrm{p}=0.028)$.

\section{Discussion}

Consistent with previous RWC studies, ${ }^{[5-7]}$ forwards were significantly taller and heavier than backs in RWC 2019 but there was no difference in the age of backs and forwards. There was no evidence of significant trends in the age, stature or body mass of backs or forwards over the period RWC 2007 to RWC 2019. The stature and body mass of RWC players over this 12 year period were similar to values reported in previous studies of elite Northern and Southern hemisphere players. ${ }^{[12,13]}$ Although backs and forwards taking part in the RWC were on average two to three years older than players competing at the elite club level, ${ }^{[12]}$ this is to be expected as the more experienced players are generally selected for the national teams. The incidence of match injury for backs was higher than that recorded for forwards in RWC 2019, which has also been reported in previous RWCs. ${ }^{[5-7]}$ The lower overall incidence of match injuries recorded in RWC 2019 compared to RWC 2015 is welcome with the reduction mainly attributable to the lower incidence of injuries recorded by forwards. Although the incidences of training injuries for both backs and forwards were higher during RWC 2019, compared with RWC 2015, the long-term downward trend in the incidence of training injuries remains.

There were no significant differences between the severities of match injuries sustained by backs and forwards during RWC 2019. The increasing trends in mean severity of match injuries reported previously for backs and forwards in the period RWC 2007 to RWC 2015,[7] did not continue in RWC 2019; however, mean severity values remain at the higher end of the previous range. Median severity values have changed little for backs and forwards over the RWC 2007 to RWC 2019 were much lower than those reported for RWC 2007 (1 065 player-days-absence) and RWC 2011 (940 player-daysabsence). ${ }^{[6,7]}$

The head/face $(21.9 \%)$, posterior thigh $(10.9 \%)$ and knee $(15.6 \%)$ are the sites of almost $50 \%$ of all injuries sustained, whilst ligament sprains $(21.7 \%)$, muscle strains $(20.3 \%)$ and concussions $(15.4 \%)$ describe almost $60 \%$ of all injury types sustained. While the two most common specific injuries (concussion: 15.4\%; hamstring muscle strain: 9.8\%) accounted for approximately 25\% of all injuries sustained in RWC 2019, they were not responsible for the most time-loss injuries, as knee ligament (22.6\%) and knee cartilage (12.0\%) injuries together accounted for nearly $35 \%$ of all time lost. Although there was a small increase in match concussions in RWC 2019 compared to RWC 2015 (15.5\% v 13.9\%; p = 0.582), when expressed as a percentage of all match injuries sustained, the incidence of concussion was slightly lower in RWC 2019 than RWC 2015 (12.2 v 12.5 injuries/1 000 player-match-hours; p = 0.912 ) due to the overall reduction in injury incidence in RWC 2019. A comparison of concussions sustained in the 2007, 2011 and 2015 RWCs has been presented previously. ${ }^{[7]}$. Despite concussions currently being the focus for injury prevention in rugby, knee ligament, knee cartilage and hamstring injuries together are responsible for nearly $50 \%$ of all player-daysabsence. These injuries, therefore, must not be overlooked, as they are likely to provide a greater return on any investment in injury prevention. ${ }^{[14]}$

The tackle (tackling: 28.7\%; being tackled: 19.1\%) was responsible for $47.8 \%$ of all injuries sustained in RWC 2019, which continues the upward trend in the proportion of injuries sustained in the tackle observed in previous RWCs (2007: 29.2\%; 2011: 40.1\%; 2015: 45.9\%) $)^{[5-7]}$. A number of previous studies have investigated relationships between match injuries and specific match activities ${ }^{[15-18]}$.

This study has a number of strengths: it is a prospective, whole population study following the recommendations of the consensus statement on injury definitions and data collection procedures for studies of injuries in rugby union. ${ }^{[4]}$ The study describes the sample populations in terms of players' position, age, stature and body mass. Injuries and illnesses were diagnosed and reported by qualified team doctors and 
physiotherapists, using an established reporting protocol and the Orchard Sports Injury Classification System. Furthermore, all injuries and illnesses were followed up post-tournament in order to obtain final diagnoses and return to play dates. In conclusion, the results from this study confirm a high incidence and severity of injury within international rugby but the incidence, nature and inciting events for injuries in RWC 2019 were broadly similar to those reported previously for RWC 2007, 2011 and 2015.

Conflict of interest: CWF provides risk management consultancy services to World Rugby. MD is World Rugby's research, turf and equipment manager. MR was World Rugby's Chief Medical Officer at the time of RWC 2019. AT has no competing interest.

Source of funding: The study was funded by World Rugby. The funders had no role in the study design, data collection and analysis or the preparation of the manuscript.

Acknowledgements: The authors would like to acknowledge the valuable support provided by medical staff from the 20 participating national teams who provided injury data for this study: F Badessi, G Botto, C Cosgrave, M Deasy, F Fujita, D Gutierrez, W Harrington, C Jenkins, W MacDonald, J Mampane, P Mathema, V Morkel, K Ng, T Page, P Poloniati, S Pope, J Robson, M Santurio, B Savill, N Shamatava, S Takamori, M White, D Williams, O Withers, M Yamada, R Youngs.

\section{Author contributions:}

CWF designed the study, analysed and interpreted the data, and wrote the initial draft and final version of the paper. AT contributed to the design of the study, collected the data and critically assessed the initial draft of the paper. MD contributed to the design of the study, collected the data, and critically assessed the initial draft of the paper. MR contributed to the design of the study, interpretation of the results, and critically assessed the initial draft of the paper. All authors approved the final version of the paper.

\section{References}

1. Fuller C, Drawer S. The application of risk management in sport. Sports Med 2004; 34(6): 349-356. [doi:10.2165/00007256200434060-00001] [PMID: 15157119]

2. Fuller CW. Managing the risk of injury in sport. Clin J Sport Med 2007; 17: 182-187. [doi: 10.1097/JSM.0b013e31805930b0] [PMID: 17513908]

3. World Rugby. World Rugby guidelines - what are they? Available at https://playerwelfare.worldrugby.org/ ?subsection=66 (Accessed: 11 April 2020).
4. Fuller CW, Molloy MG, Bagate C, et al. Consensus statement on injury definitions and data collection procedures for studies of injuries in rugby union. Clin J Sport Med 2007; 17: 177-181. [doi: 10.1097/JSM.0b013e31803220b3] [PMID: 17513907]

5. Fuller CW, Laborde F, Leather RJ, et al. International Rugby Board Rugby World Cup 2007 injury surveillance study. Br J Sports Med 2008; 42(6): 452-459. [doi: 10.1136/bjsm.2008.047035] [PMID: 18539659]

6. Fuller CW, Sheerin K, Targett S. Rugby World Cup 2011: International Rugby Board injury surveillance study. Br J Sports Med 2013; 47(18): 1184-1191. [doi: 10.1136/bjsports-2012091155] [PMID: 22685124]

7. Fuller CW, Taylor AE, Kemp SP et al. Rugby World Cup 2015: World Rugby injury surveillance study. Br J Sports Med 2017; 51(1): 51-57. [doi: 10.1136/bjsports-2016-096275] [PMID: 27461882]

8. Orchard J, Rae K, Brooks J, et al. Revision, uptake and coding issues related to the open access Orchard Sports Injury Classification System (OSICS) versions 8, 9 and 10.1. Open Access J Sports Med 2010; 1: 207-214. [doi: 10.2147OAJSM.S7715] [PMID: 24198559]

9. Drawer S, Fuller CW. Evaluating the level of injury in English professional football using a risk based assessment process. $\mathrm{Br}$ J Sports Med 2002; 36(6): 446-451. [doi: 10.1136/bjsm.36.6.446] [PMID: 12453840]

10. Fuller CW. Injury risk (burden), risk matrices and risk contours in team sports: a review of principles, practices and problems. Sports Med 2018; 48(7): 1597-1606. [doi: 10.1007/s40279-0180913-5] [PMID: 29623603]

11. Kirkwood BR, Sterne JA. Essential medical statistics. $2^{\text {nd }}$ ed. Oxford: Wiley-Blackwell 2003.

12. Fuller CW, Taylor AE, Brooks JH, et al. Changes in the stature, body mass and age of English professional rugby players: a 10year review. J Sports Sci 2013; 31(7): 795-802. [doi: 10.1080/02640414.2012.753156] [PMID: 23244349]

13. Zemski AJ, Slater GJ, Broad EM. Body composition characteristics of elite Australian rugby union athletes according to playing position and ethnicity. J Sports Sci 2015; 33(9): 970-978. [doi: 10.1080/02640414.2014.977937] [PMID: 25553727]

14. Fuller CW. Assessing the return on investment of injury prevention procedures in professional football. Sports Med 2019; 49(4): 621-629. [doi: 10.1007/s40279-019-01083-z] [PMID: 30838519]

15. Fuller CW, Brooks JH, Cancea RJ, et al. Contact events in rugby union and their propensity to cause injury. Br J Sports Med 2007; 41(12): 862-867. [doi:10.1136/bjsm.2007.037499] [PMID: 17513332]

16. Quarrie KL, Hopkins WG. Tackle injuries in professional rugby union. Am J Sports Med 2008; 36(9): 1705-1716. [doi:10.1177/0363546508316768] [PMID: 18495967]

17. Fuller $\mathrm{CW}$, Ashton $\mathrm{T}$, Brooks JH, et al. Injury risks associated with tackling in rugby union. Br J Sports Med 2010; 44(3):159167. [doi: 10.1136/bjsm.2008.050864] [PMID:18723553]

18. McIntosh AS, Savage TN, McCrory P, et al. Tackle characteristics and injury in a cross section of rugby union football. Med Sci Sports Exerc 2010; 42(5): 977-984. [doi:10.1249/MSS.0b013e3181c07b5b] 